Jurnal Indonesia Sosial Teknologi: p-ISSN: 2723 - 6609

e-ISSN : 2745-5254

Vol. 2, No. 6 Juni 2021

\title{
ANALISA TEGANGAN PIPA UNTUK 20" STEAM PIPING MENGGUNAKAN SOFTWARE CAESAR II
}

\author{
Khairiah Dongoran dan Koswara \\ Program Studi Magister Teknik Mesin, Fakultas Pasca Sarjana, Institut Sains Dan \\ Teknologi Nasional. \\ Email: dongoranria4@gmail.com,dtkoswara@yahoo.co.id
}

\begin{abstract}
Abstrac
In the piping system design process, static analysis and dynamic analysis need to be carried out to ensure the design safety and operational security of the piping system. In this article, the design and design of new Steam Lines is carried out to determine the pipe stress on Steam Piping, the effect of the forces and moments caused on the piping system conditions and determine the appropriate support for the piping system design. The purpose of this study is to determine the suitability of the stress analysis with the ASME B31.3 code used and to ensure the safety of the piping system including all its components. The method used in completing the analysis is modeling the piping system using Caesar II software and using literature studies. From the results of the maximum stress analysis shown in these two analytical methods, both manual calculations / Manual Calculation and Caesar II programs as shown in table 3 are still acceptable, namely: Caesar II for Expansion conditions (EXP) the value is $96.7 \%$, while for manual calculations the value is $26.3 \%$. By adding the support shown in Table 2 the stresses, displacements, forces and moments that occur on the Steam Piping Acceptable during operation both in terms of safety and design.
\end{abstract}

Keyword : piping system; piping process; support; voltage

\begin{abstract}
Abstrak
Dalam proses perancangan sistem perpipaan, analisa statis dan analisa dinamis perlu dilakukan untuk menjamin keamanan rancangan dan keamananan operasional dari sistem perpipaan. Dalam artikel ini Perancangan dan desain Steam Lines baru dilakukan untuk mengetahui Tegangan pipa pada Steam Piping, Pengaruh gaya dan momen yang ditimbulkan terhadap kondisi piping sistem dan menentukan support yang sesuai untuk desain piping sistem. Tujuan dari penelitian ini untuk mengetahui kesesuaian analisa tegangan dengan code ASME B31.3 yang digunakan serta memastikan keselamatan sistem perpipaan termasuk semua komponennya. Metode yang digunakan dalam menyelesaikan analisis yaitu melakukan pemodelan sistem perpipaan dengan menggunakan perangkat lunak software Caesar II serta menggunakan studi literature. Dari hasil analisis tegangan maksimum yang ditunjukkan pada kedua metode analisa ini baik perhitungan manual / Manual Calculation maupun program Caesar II seperti yang ditunjukkan pada tabel 3 masih dapat diterima yaitu: Caesar II untuk kondisi Expansi (EXP) nilainya $96.7 \%$, Sedangakan untuk perhitungan manual nilainya $26.3 \%$. Dengan menambahkan support yang ditunjukkan pada Tabel 2 tegangan, displacement, gaya dan momen
\end{abstract}


yang terjadi pada Steam Piping Acceptable selama beroperasi baik dari segi keselamatan maupun desain.

Kata kunci: sistem perpipaan; piping process; support; tegangan

\section{Pendahuluan}

Dalam proses perancangan sistem perpipaan, analisa statis dan analisa dinamis perlu dilakukan untuk menjamin keamanan rancangan dan keamananan operasional dari sistem perpipaan (Greer, Harper, \& Eng, 2012). Analisa statis sistem perpipaan dipengaruhi oleh berat, ekspansi thermal, perpindahan support, tekanan internal dan tekanan eksternal (Kannappan, 1986). Beban statis merupakan beban yang disebabkan oleh pengaruh internal seperti tekanan, temperatur, berat pipa dan berat komponen yang terdapat pada sistem perpipaan (Chamsudi, 2005).

PT FS adalah produsen kertas kemasan terkemuka di Indonesia yang sudah terpasang kapasitas 1.300.000 metrik ton per tahun dan berbagai produk yang meliputi Kraft Liner Board dan Corrugated Medium Paper untuk kemasan dus karton dan Coated Duplex Papan untuk kemasan display. Perusahaan ini berencana menambah steam lines untuk mengeluarkan uap yang diperlukan dari GT-3 ke Paper Machine (PM) untuk mendukung produksi. Perancangan steam lines baru termasuk pemasangan pipa, ketebalan, perhitungan ukuran, jenis dukungan, perutean pipa, lokasi dan analisis stress (Habibah, n.d.). Kode perpipaan dasar yang digunakan dalam penelitian ini adalah ASME B31.3 (Becht, 2013). Analisa kelelahan pada sistem perpipaan di Offshore Platform. Analisa dilakukan untuk mempelajari pengaruh beban siklis akibat gelombang terhadap sistem perpipaan. Acuan yang digunakan adalah ASME B31.3 dan menggunakan bantuan software simulasi CAESAR II (Hewapathirana, 2012). Tegangan dan fenomena fatigue pada pipa fleksibel (flexible risers) dengan pendekatan metode elemen hingga (Li, 2012). Tegangan terhadap rancangan sistem perpipaan steam power plant menggunakan CAESAR II, terutama akibat pengaruh adanya hanger dan expansion joint. Sehingga tujuan utamanya adalah untuk memperoleh fleksibilitas sistem perpipaan yang cukup untuk mengatasi beban ekspansi thermal, disamping pemenuhan terhadap kriteria tegangan dan displacement (Rani \& Ramanathan, 2016).

Tujuan penelitian ini untuk merancang sistem perpipaan Steam Trap 20"dari Steam Header ke Tie-In Point selama hydro test dan operational condition, agar integritas kekuatan perpipaan sesuai kode desain ASME B31.3 dengan bantuan program komputer CAESAR II serta Melakukan komparasi hasil dengan perhitungan manual (Rachmanu, Santoso, \& Arumsari, 2017).

\section{Metode Penelitian}

Pemodelan dan simulasi dilakukan untuk mengevaluasi pengaruh jenis dukungan/support, perutean pipa, lokasi dan analisis stress terhadap besarnya teganganTegangan statis yang terjadi, apakah masih memenuhi kriteria tegangan ijin menurut ASME B31.3. Tegangan yang bekerja pada sistem perpipaan yang dianalisa adalah 
tegangan akibat beban sustain dan tegangan akibat beban ekspansi thermal. Kode standar (load case) yang digunakan adalah Load Case-L4 (W-P1) untuk perhitungan tegangan akibat beban ekspansi dan Load Case-29 (L29 = L2 - L4) untuk perhitungan tegangan akibat beban ekspansi thermal (Husodo \& Mahardhika, 2019). Alur penelitian untuk menghitung tegangan akibat beban sustain dan tegangan akibat beban ekspansi thermal dapat dilihat pada Gambar 1.

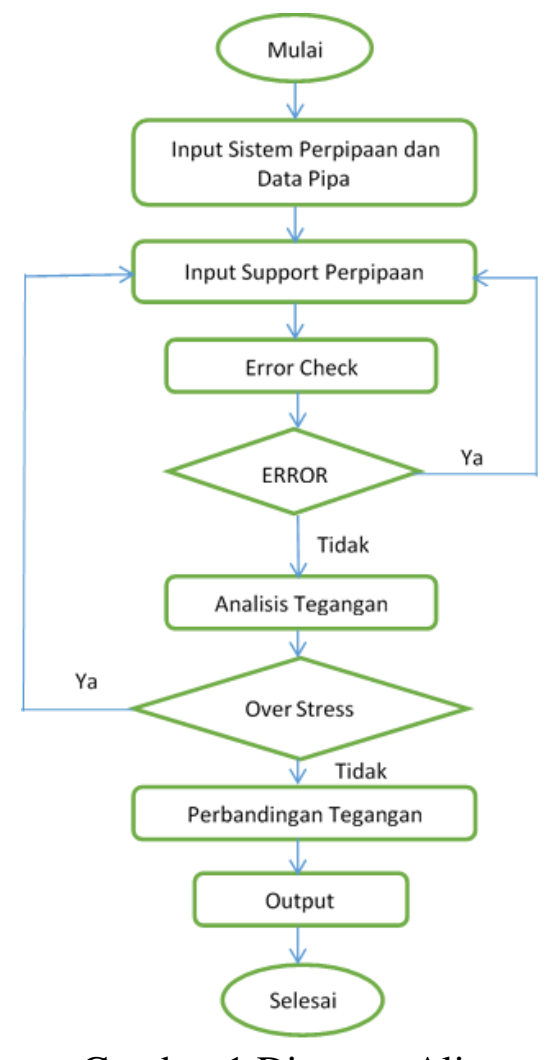

Gambar 1 Diagram Alir

Analisa dilakukan dengan Sofware Caesar II 2018. Data-datanya sebagai berikut

$\begin{array}{lll}\text { Diameter pipa } & : & 6 " \\ \text { Sch } & : & 160 \\ \text { Insulation } & : & 200 \mathrm{~mm} \\ \text { Design Pressure } & : & 98 \mathrm{bars} \\ \text { Design Temperature } & : & 530{ }^{\circ} \mathrm{C} \\ \text { Hydro Test Pressure } & : & 147 \mathrm{bars} \\ \text { Diameter pipa } & : & 20 ”, 10^{\prime}, 1 ” \\ \text { Sch } & : & 40 \\ \text { Insulation } & : & 100 \mathrm{~mm}, 50 \mathrm{~mm}, 30 \mathrm{~mm} \\ \text { Design Pressure } & : & 13 \mathrm{bars} \\ \text { Design Temperature } & : & 250^{\circ} \mathrm{C} \\ \text { Hydro Test Pressure } & : & 19.5 \mathrm{bars}\end{array}$


Analisa Tegangan Pipa untuk 20" Steam Piping Menggunakan Software Caesar Ii

$\begin{array}{lll}\text { Material Specification } & : & \text { ASTM A106 Gr.B } \\ \text { Fluid Density } & : & 5.652 \mathrm{~kg} / \mathrm{m}^{3} \\ \text { Insulation Density } & : & 75 \mathrm{~kg} / \mathrm{m}^{3}\end{array}$

\section{Hasil dan Pembahasan}

Dalam menghitung tegangan yang terjadi pada sistem perpipaan ini akan dibandingkan dengan hasil hitungan software CAESAR II yaitu dengan memasukkan hasil analisanya keperhitungan manual sebagai perbandingan. Langkah-langkah perhitungan secara manual menurut sumber buku "Introduction of pipe stress analysis" by Sam Kannnappan PE, (C) 1986 dan juga telah mengacu kepada ASME B31.3 adalah sebagai Berikut :

- Menghitung Longitudinal Stress

$$
\begin{aligned}
& \mathrm{SL}=\mathrm{E} \alpha\left(\mathrm{T}_{2}-\mathrm{T}_{1}\right)-\left(v P\left(\frac{D-2 t}{2 t}\right)\right) \\
& \mathrm{SL}=13715 \mathrm{psi}
\end{aligned}
$$

- Menghitung tegangan Tangensial / Hoop Stress (Si)

$$
S i=P\left(\frac{D-2 t}{2 t}\right)
$$

$S i=2986$ psi

- Perhitungan Beban

a) Beban Sustain

$$
\begin{aligned}
& S_{L}=S_{b}+S_{L P}<0.75 . S . F . ~ T \\
& S_{L}=5326<10,500
\end{aligned}
$$

b) Beban Expansion

$$
\begin{aligned}
& \mathrm{Se}=\left(\mathrm{Sb}^{2}+4 \mathrm{~S}_{\mathrm{t}}^{2}\right)^{1 / 2} \leq 0.72 \mathrm{~S} \\
& \mathrm{Se}=5970<22,680
\end{aligned}
$$

c) Beban Operating

$$
\text { Sope }=S_{e}+S_{L}<S
$$

d) Beban Occasional

$$
\begin{aligned}
& S_{o c c}=S_{e}+S_{L}<0.75 . \text { Syield. F. T. K } \\
& S_{\text {occ }}=10093<23625
\end{aligned}
$$

Model CAESAR II berdasarkan pada gambar isometrik seperti yang diberikan pada Gambar 2 di bawah ini 


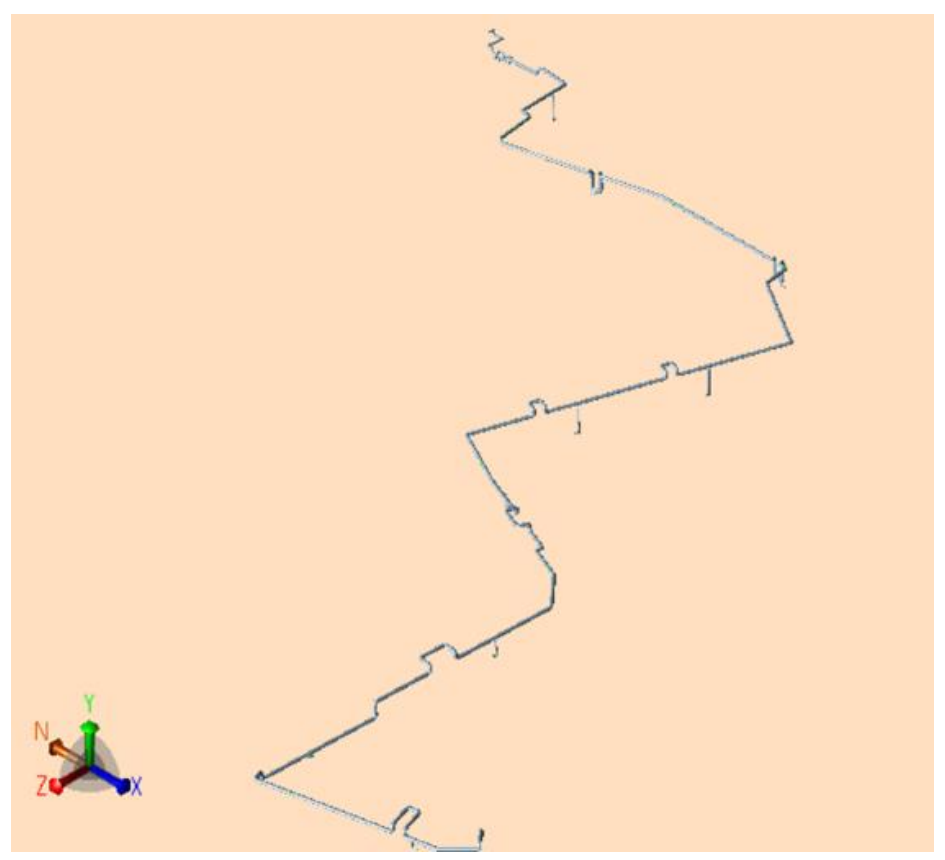

Gambar 2 Model CAESAR II Southeast Isometric View

\section{1) Restraint Modeling}

Untuk memodelkan karakteristik kekakuan sistem pipa sedekat mungkin dengan kenyataan di lapangan, perlu untuk memodelkan Support yang sesuai. Rancangan support suatu sistem perpipaan merupakan kegiatan iteratif yang sangat terkait dengan tegangan statis yang terjadi (Nayyar, 2000). Dalam sistem perpipaan yang dianalisis, terdapat Support tambahanan yang ditunjukkan pada Tabel 1

Tabel 1 Support Type

\begin{tabular}{cccc}
\hline Node \# & Support Type & Node \# & Support Type \\
\hline 120 & Guide & 1300 & Guide \\
\hline 200 & Guide & 1320 & Guide \\
\hline 230 & Guide, Stopper (LIM) & 1410 & Guide \\
\hline 280 & Guide & 1440 & Guide \\
\hline 285 & Stopper (LIM) & 1450 & Stopper (LIM) \\
\hline 310 & Guide & 1480 & Stopper (LIM) \\
\hline 360 & Guide & 1490 & Guide \\
\hline 460 & Guide & 1650 & Guide \\
\hline 490 & Guide & 1720 & Guide \\
\hline 550 & Stopper (LIM) & 1795 & Guide \\
\hline 560 & Guide & 1850 & Resting (+Y) \\
\hline 680 & Guide & 1972 & Resting (+Y) \\
\hline 710 & Guide, Stopper (LIM) & 2070 & Guide, Stopper (LIM) \\
\hline 760 & Guide, Stopper (LIM) & 3175 & Resting (+Y) \\
\hline 860 & Guide & 3595 & Resting (+Y) \\
\hline 880 & Stopper (LIM) & 3605 & Resting (+Y), \\
\hline 900 & Guide & 3675 & Stopper (LIM) \\
\hline 990 & Guide & 3745 & Resting (+Y) \\
\hline 1020 & Guide & 3815 & Resting (+Y) \\
\hline 1030 & Stopper (LIM) & 7070 & Stopper (LIM) \\
\hline & & &
\end{tabular}


Analisa Tegangan Pipa untuk 20" Steam Piping Menggunakan Software Caesar Ii

\begin{tabular}{cccc}
\hline 1130 & Guide, Stopper (LIM) & 8090 & Stopper (LIM) \\
\hline 1230 & Guide & 9090 & Stopper (LIM) \\
\hline 1250 & Guide & 10090 & Stopper (LIM) \\
\hline 1270 & Guide & 13090 & Stopper (LIM) \\
\hline 1285 & Guide, Stopper (LIM) & - & - \\
\hline
\end{tabular}

2) Stress Summary

Berikut adalah tegangan maksimal Steam Piping dengan Mempertimbangan pemasangan Support hasil analisis fleksibilitas perpipaan tidak ada tegangan berlebih (Pridyatama \& Kurniawan, 2014).

Tabel 2 Maximum Stress

\begin{tabular}{|c|c|c|c|c|c|}
\hline Node \# & Cases & $\begin{array}{l}\text { Actual Stress } \\
\text { (KPa) }\end{array}$ & $\begin{array}{c}\text { Allowable } \\
\text { Stress (KPa) }\end{array}$ & $\begin{array}{c}\text { Ratio } \\
(\%)\end{array}$ & Remark \\
\hline 1850 & (HYD)WW+HP & 24582.5 & 30000 & 81.9 & PASSED \\
\hline 6000 & (Alt-SUS)W+P1 & 16223.1 & 19162.3 & 84.6 & PASSED \\
\hline 1920 & (SUS) W+P1 & 5772.2 & 8788.4 & 65.6 & PASSED \\
\hline 2240 & (OCC)L21=L13+L4 & 6455.88 & 11688.5 & 55.2 & PASSED \\
\hline 2240 & (OCC)L22=L14+L4 & 6451.6 & 11688.5 & 55.2 & PASSED \\
\hline 1930 & $(O C C) \mathrm{L} 23=\mathrm{L} 15+\mathrm{L} 4$ & 8270.9 & 11688.5 & 70.7 & PASSED \\
\hline 1930 & (OCC)L24=L16+L4 & 8264.8 & 11688.5 & 70.7 & PASSED \\
\hline 1920 & (OCC)L25=L17+L4 & 5778.2 & 11688.5 & 49.4 & PASSED \\
\hline 1920 & (OCC)L26=L18+L4 & 5778.1 & 11688.5 & 49.4 & PASSED \\
\hline 1920 & (OCC)L27=L19+L4 & 5810 & 11688.5 & 49.7 & PASSED \\
\hline 1920 & (OCC)L28=L20+L4 & 5810 & 11688.5 & 49.7 & PASSED \\
\hline 930 & (EXP)L29=L2-L4 & 45031.5 & 46565.8 & 96.7 & PASSED \\
\hline
\end{tabular}

3) Komparasi hasil stress analysis

Hasil perhitungan semua sistem perpipaan dengan menggunakan sumber dari buku "introduction of pipe stress analysis", by Sam (Kannappan, 1986) dan dibandingkan dengan hasil perhitungan program computer CAESAR II yang mengacu pada ASME B31.3 didapat pada tabel sebagai berikut :

Tabel 3 Komparasi/perbandingan

\begin{tabular}{|c|c|c|c|c|c|c|c|}
\hline \multirow{4}{*}{$\begin{array}{l}\text { Load } \\
\text { Condition }\end{array}$} & \multirow{2}{*}{\multicolumn{2}{|c|}{$\begin{array}{c}\text { Result stress } \\
\text { (Кра) }\end{array}$}} & \multirow{2}{*}{\multicolumn{2}{|c|}{$\begin{array}{c}\text { Allowable stress } \\
\text { (Кра) }\end{array}$}} & \multirow{2}{*}{\multicolumn{2}{|c|}{$\begin{array}{c}\text { Stress Ratio } \\
(\%)\end{array}$}} & \multirow{4}{*}{ Remark } \\
\hline & & & & & & & \\
\hline & Manual & Caesar & Manual & Caesar & Manual & \multirow{2}{*}{ Caesar II } & \\
\hline & Calc. & II & calc. & II & calc. & & \\
\hline $\begin{array}{c}\text { Operating } \\
\text { (OPE) }\end{array}$ & 69588.8 & 24582.5 & 72394.9 & 30000 & 32 & 81.9 & Acc \\
\hline $\begin{array}{c}\text { Sustain } \\
\text { (SUS) }\end{array}$ & 36721.4 & 5772.2 & 156373.1 & 8788.4 & 50.7 & 84.6 & Acc \\
\hline
\end{tabular}


Khairiah Dongoran dan Koswara

\begin{tabular}{llllllll}
\hline \begin{tabular}{c} 
Occasional \\
\hline (OCC)
\end{tabular} & 77462.6 & 8270.9 & 217184.9 & 11688.5 & 47.5 & 70.7 & Acc \\
\cline { 1 - 4 } \begin{tabular}{c} 
Expansion \\
\hline (EXP)
\end{tabular} & 41161.7 & 45031.5 & 162888.7 & 46565.8 & 26.3 & 96.7 & Acc \\
\hline
\end{tabular}

\section{Kesimpulan}

Hasil Dari hasil analisis tegangan maksimum yang ditunjukkan pada kedua metode analisa ini baik perhitungan manual / Manual Calculation maupun program CAESAR II seperti yang ditunjukkan pada tabel 3 masih dapat diterima yaitu: CAESAR II untuk kondisi Expansi (EXP) nilainya $96.7 \%$, Sedangakan untuk perhitungan manual nilainya $26.3 \%$. Dengan menambahakan support yang ditunjukkan pada Tabel 2 tegangan, displacement, gaya dan momen yang terjadi pada Steam Piping Acceptable selama beroperasi baik dari segi keselamatan maupun desain. 


\section{Bibliography}

Becht, Charles. (2013). Power Piping: The Complete Guide to ASME B31. 1. ASME Press.

Chamsudi, Ahmad. (2005). Diktat-Piping Stress Analysis. Jakarta: Chamsudi Copyright.

Greer, Bryan, Harper, Chris, \& Eng, P. (2012). Improved Thermal Piping Analysis for Reciprocating Compressor Piping Systems. Gas, 2012.

Habibah, Farhani. (n.d.). Desain Penambahan Jalur Perpipaan Tie-in Point Akibat Penambahan Deliquidizer.

Hewapathirana, Pubudu. (2012). Fatigue analysis of offshore piping systems. University of Stavanger, Norway.

Husodo, Adi Wirawan, \& Mahardhika, Pekik. (2019). ANALISA FLEKSIBILITAS SISTEM PERPIPAAN PADA FATTY ACID PLANT AKIBAT PERGESERAN POSISI EVAPORATOR. Jurnal Integrasi, 11(2), 112-118.

Kannappan, Sam. (1986). Introduction to pipe stress analysis.

Li, Henan. (2012). Flexible Pipe Stress and Fatigue Analysis. Institutt for marin teknikk.

Nayyar, Mohinder L. (2000). Piping handbook. McGraw-Hill Education.

Pridyatama, Parada Anugerah, \& Kurniawan, Budi Agung. (2014). Analisa Rancangan Pipe Support pada Sistem Perpipaan High Pressure Vent Berdasarkan Stress Analysis dengan Pendekatan Caesar II. Jurnal Teknik ITS, 3(2), F168-F173.

Rachmanu, Tri Handika, Santoso, Mardi, \& Arumsari, Nurvita. (2017). Analisa Tegangan Pipa Main Steam Dari Outlet Superheater Menuju Inlet Turbin Studi Kasus PLTU Tembilahan $2 \times 7$ MW. Proceedings Conference on Piping Engineering and Its Application, 2(1), 21-26.

Rani, M. Jamuna, \& Ramanathan, K. (2016). Design and analysis of piping system with supports using Caesar-II. International Journal of Computer and Systems Engineering, 10(5), 980-984. 